\title{
ENUNCIADOS DE CURTA EXTENSÃO: GÊNERO DE DISCURSO, AFORIZAÇÃO, MÍDIA E POLÍTICA
}

\section{Roberto Leiser Baronas*}

Resumo: Nosso interesse primeiro neste trabalbo é tentar compreender o papel da máquina midiática nos processos de produção, circulação e de fabricação das informações politicas sobre as eleições presidenciais brasileiras 2010. Para tanto, ancorados na Análise do Discurso, mais especificamente nos trabalhos de Dominique Maingueneau (2007, 2010a e 2010b), frequentamos um corpus constituído por pequenos enunciados atribuidos aos candidatos Dilma Rousseff e José Serra e veiculados pela mídia eletrônica brasileira em 2010. Inicialmente, procuramos definir as características do "enunciado de curta extensão", diferenciando-o de outros como slogans e provérbios; num segundo momento, evidenciamos, por um lado, as características enunciativas dessas pequenas frases que visam favorecer ao seu destaque e, por outro, os determinantes genéricos, linguísticos e semióticos utilizados pelos locutores midiáticos no destaque desses enunciados e, por último, descrevemos como esses enunciados são destextualizados de seus cotextos originais, procurando compreender como são submetidos ao regime discursivo da aforização.

Palavras-chave: Discurso político. Enunciado de curta extensão. Aforização e mídia.

\section{PRIMEIRAS PALAVRAS}

Neste trabalho, tomamos como objeto de análise discursiva pequenos enunciados que circularam na mídia impressa brasileira durante os meses de março a setembro de 2010, durante a campanha eleitoral desse ano, e que foram atribuídos aos candidatos a presidente do Brasil mais bem colocados nas pesquisa de intenção de votos: Dilma Rousseff (PT) e José Serra (PSDB). Tais enunciados foram dados a circular em pequenos textos quase que diariamente no site do Universo On Line UOL, ora na seção Eleições 2010 - Últimas Notícias ou no Folha On Line. Esses textos possuíam geralmente uma página e também vários links para outros artigos. Alguns ao lado das frases traziam fotografias dos candidatos. Eram assinados ou por diferentes jornalistas ou creditados a uma equipe da editoria de política do site e todos,

\footnotetext{
* Professor da Universidade Federal de São Carlos. Professor Colaborador no Mestrado em Estudos da Linguagem da UFMT. Pesquisador do CNPq. Doutor em Linguística e Língua Portuguesa. Email: baronas@ufscar.br.
} 
rigorosamente, traziam o horário em que foram publicados. De março a setembro construímos um arquivo documental com 45 textos cuja temática era basicamente ora a agenda de compromissos de campanha dos candidatos José Serra e Dilma Rousseff ou os fatos políticos brasileiros que à época geraram maior polêmica. Para este trabalho frequentamos excertos de 6 textos: três com enunciados atribuídos à candidata Dilma Rousseff e três com pequenas frases atribuídas a José Serra. Detivemo-nos mais especificamente no processo de destextualização $0^{1}$ da fala dos candidatos, realizado pelos jornalistas, e a sua consequente colocação em relevo, transformando-a em título de manchete. Como marco teórico-metodológico mobilizamos a Análise de Discurso de orientação francesa, sobretudo os trabalhos de Dominique Maingueneau (2007, 2010a e 2010b) sobre citação, destacabilidade, sobreasseveração e enunciação aforizante.

\section{ENUNCIADOS DE CURTA EXTENSÃO: GÊNEROS DO DISCURSO?}

Os enunciados de curta extensão tais como os slogans, os provérbios, os aforismos, as máximas, podem, por um lado, ser enquadrados, por conta mesmo de sua materialidade significante, como enunciados sintaticamente semelhantes, dado o número reduzido de vocábulos que mobilizam na sua organização frasal, isto é, geralmente sua extensão não ultrapassa uma frase; por outro lado, no tocante às suas propriedades linguístico-discursivas, cada um desses enunciados possui características próprias. Cada uma dessas pequenas frases mobiliza recursos linguísticos (estilísticos, frasais), temáticos e composicionais bastante específicos. Assim, com base em Mikhail Bakhtin (1984), podemos dizer que cada um desses enunciados constitui um gênero ou

\footnotetext{
1 Maingueneau (2010b) chama de destextualização "une opération de mise en relief par rapport à l'environnement textuel qui s'effectue à l'aide de marqueurs divers: d'ordre aspectuel (généricité), typographique (position saillante dans une unité textuelle), prosodique (insistance), syntaxique (construction d'une forme prégnante), sémantique (recours aux tropes), lexical (utilisation de connecteurs de reformulation)..." Em outras palavras, destextualização é o processo no qual um enunciado é destacado de um texto maior e passa a circular em outro, geralmente como manchete de imprensa, título ou intertítulo. Todavia, o enunciado destacado sempre se apresenta com sentido diferente em relação ao sentido primeiro.
}

BARONAS - Enunciados de curta extensão... 
um microgênero discursivo distinto. Por exemplo, enquanto um $\operatorname{slogan}^{2}$ geralmente neutraliza a dicotomia existente entre a modalidade escrita e a modalidade falada, está sempre muito atento às inovações linguísticas dos mais variados grupos sociais e às moedas linguísticas mais valorizadas no mercado; opta geralmente por verbos no imperativo; é atravessado por diversos outros gêneros tais como o provérbio, a máxima, a palavra de ordem, etc, e aparece em circunstâncias comunicacionais mais complexas tais como a escrita; o provérbio, ao contrário, por fazer parte da sabedoria popular, do Thesaurus Cultural de um determinado grupo social, se apresenta mais resistente à neutralização da dicotomia entre a escrita e a fala, às inovações linguísticas e às moedas linguísticas mais valorizadas no mercado; opta frequentemente por verbos no indicativo; geralmente é pouco atravessado por outros gêneros e aparece em circunstâncias comunicacionais como a oralidade. Ademais, é possível dizer que vários provérbios se transformaram em slogans, entretanto o contrário é muito mais difícil de acontecer. Assim, bakhtinianamente falando, diríamos que enquanto o slogan se constitui num gênero secundário, o provérbio ${ }^{3}$, dada a sua proximidade mesmo com a oralidade, se constitui num gênero primário.

\section{ENUNCIADOS DE CURTA EXTENSÃO E SOBREASSEVERAÇÃO}

Todavia, se pensarmos estes enunciados do ponto de vista do destacamento do contexto situacional e do cotexto original em que são produzidos, verificaremos que o conceito de gênero discursivo não dá conta de descrever as complexas relações estabelecidas entre os enunciados e os textos que os alojam. Estes enunciados, se por um lado dependem de um gênero discursivo que os aninhe, que lhes dê guarida, por outro, extrapolam todo e qualquer gênero. Ou seja, estes enunciados,

\footnotetext{
${ }^{2}$ É preciso dizer que o slogan se apresenta com valores distintos quando se trata de slogan publicitário e quando se trata de slogan político.

${ }^{3}$ Sobre a enunciação proverbial vale a pena conferir o artigo "Polifonia, provérbio e desvio" de Dominique Maingueneau em Doze conceitos em análise do discurso, São Paulo: Parábola Editorial, 2010, bem como a tese "Heterogeneidade e aforização: uma análise do discurso dos Racionais MC" de Ana Raquel Motta de Souza, defendida no IEL-Unicamp em 2009.
} 
apesar de estarem inscritos num determinado gênero discursivo, por conta mesmo do seu destaque, acabam por adquirir autonomia discursiva em relação ao texto primeiro, se constituindo num texto outro com sentido próprio. Acreditamos, com base em Maingueneau (2010a), que entre os enunciados destacados e o gênero discursivo existe uma relação de destextualização, isto é, de saída do enunciado do gênero e a inscrição em outro contexto discursivo.

Além dos slogans, dos provérbios, circula na nossa sociedade, sobretudo nos mais variados suportes midiáticos, um conjunto de outros pequenos enunciados que, apesar de possuírem características linguísticas semelhantes às dos provérbios, dos slogans, não se enquadram nem na categoria do primeiro e nem na do segundo. Trata-se, no entendimento de Maingueneau (2007, p.79)4, de formas linguístico-discursivas sobreasseveradas que se apresentam como elementos:

a) relativamente breves, de estrutura pregnante no plano do significado e/ou do significante; b) [estão] em posição relevante no texto ou em uma passagem do texto, de modo a lhe[s] atribuir o estatuto de um condensado semântico, o produto de uma espécie de sedimentação da realização do discurso; c) [...] sua temática deve estar em relação com o intuito do gênero de discurso, do texto em questão: trata-se de uma tomada de posição [grifo nosso] no interior de um conflito de valores; d) implica um tipo de "amplificação" da figura do enunciador, manifestada por um ethos apropriado.

No entanto, em seus contextos de circulação, sobretudo na esfera midiática, tais enunciados não se apresentam sempre da mesma forma. Assim, no entendimento de Maingueneau (2010a, p.10) os enunciados destacados que compõem manchetes de artigos de imprensa, ditos, intertítulos, etc., podem ser inscritos em

\footnotetext{
${ }^{4}$ Embora o livro Cenas da Enunciação tenha sido reeditado pela Parábola Editorial em 2008, para este trabalho mobilizamos a edição publicada pela Criar Edições em 2007. Entre as duas edições não há diferenças substanciais no conteúdo dos artigos.
}

BARONAS - Enunciados de curta extensão... 
[...] duas classes bem diferentes, conforme o "destacamento" 1) seja constitutivo: é o caso particularmente dos provérbios e de todas as fórmulas sentenciosas que por natureza não possuem contexto situacional nem cotexto original; 2) ou seja um destacamento por extração de um fragmento de texto, quando nos encontramos em uma lógica de citação.

Os enunciados destacados constitutivos pertencem originalmente a um alhures discursivo, a um já-lá, ou seja, eles foram engendrados antes, independentemente, em outro lugar por um Sujeito Universal, em que nem o contexto situacional e nem o cotexto original são recuperáveis linguisticamente. Apesar de não podermos recuperar o seu autor, sabemos que eles pertencem à sabedoria de uma determinada comunidade, a um Thesaurus Cultural. Já os enunciados destacados por extração de um fragmento de texto são produzidos por um locutor a quem se pode atribuir a responsabilidade pela enunciação, e cujo cotexto original é recuperável linguisticamente.

Consideremos o fragmento de texto a seguir de autoria de Kamila Fernandes, publicado no site do UOL ${ }^{5}$ em 18/05/2010 às 10 h17.

\section{i) Em entrevista no Ceará, Serra diz que "pesquisa vai e vem"}

Após se esquivar durante todo o dia de ontem de comentar os resultados das duas últimas pesquisas de intenção de voto, que mostram a pré-candidata do PT à Presidência, Dilma Rousseff, à frente, o pré-candidato tucano à Presidência, José Serra, afirmou nesta terça-feira (18) em entrevista à rádio Verdes Mares, de Fortaleza, que "pesquisa vai e vem" e que a campanha eleitoral vai começar mesmo "depois da Copa". Em sua fala, Serra não admitiu estar atrás de Dilma, mas empatado. "Eu estive praticamente na frente sempre, agora tem um empate. Mas logo vai desempatar, a coisa vai andar, enfim, isso aí é mais ou menos um jogo de retratos que vão se fazendo, mas a pesquisa que importa mesmo é a pesquisa da urna, do voto", disse.

\footnotetext{
${ }^{5}$ Universo On-Line.
} 
No fragmento acima, podemos observar que o enunciado destacado da fala do locutor Serra é "pesquisa vai e vem", se constituindo no título do artigo. Com efeito, dentre as inúmeras falas do candidato do PSDB, inscritas no cotexto original, destextualiza-se um único enunciado de José Serra, colocando-o em posição de relevo em relação ao restante do texto. Poderíamos dizer que a estrutura morfossintática do enunciado "pesquisa vai e vem", o seu caráter de fórmula ${ }^{6}$, favoreceu o seu destacamento, em detrimento de outros enunciados, tais como "mas a pesquisa que importa mesmo é a pesquisa da urna, do voto", apesar de esse último enunciado possuir um caráter de conclusão e de se apresentar com um ethos professoral.

Apesar da presença do verbo de dizer, da conjunção integrante e das aspas na pequena frase que compõe o título em questão, marcas que caracterizam o discurso direto, não se trata somente de uma citação das palavras de José Serra, mas "há aqui a tensão entre uma dinâmica de textualização, que tende a integrar os constituintes do texto em uma unidade orgânica, e um fenômeno que propus chamar de 'sobreasseveração' [...], que abre a possibilidade de uma saída do texto,

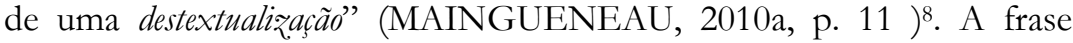
"pesquisa vai e vem", ao ser sobreasseverada pelo enunciador jornalista,

\footnotetext{
${ }^{6}$ Krieg-Planque, (2003) em sua tese de doutorado, ao analisar a fórmula "purificação étnica" posta a circular durante os anos noventa em textos de diversos jornais franceses, cuja temática eram os conflitos étnicos na antiga Iugoslávia, realizou, de certa maneira, uma história de palavras: a das quatro palavras que são "purificação", "limpeza", "depuração" e "étnica". A pesquisadora francesa procurou estudar os momentos, na história dos discursos, em que essas palavras entram em conjunção para formar os sintagmas neológicos "purificação étnica", "limpeza étnica" e "depuração étnica". Na verdade, ela buscou compreender como, no prisma dessas formulações, a guerra da exIugoslávia havia sido interpretada nas mídias francesas. Em outras palavras, ela procurou esclarecer em que medida a fórmula "purificação étnica" pode funcionar como interpretante para alguns dos comentadores das guerras iugoslavas. Por fórmula a pesquisadora francesa entende: "um conjunto de formulações que, pelo fato de serem empregadas em um momento e em um espaço público dados, cristalizam questões políticas e sociais que essas expressões contribuem, ao mesmo tempo, para construir". Uma versão condensada da tese de Krieg-Planque (2003) foi publicada com o título de "A noção de "fórmula" em análise do discurso - quadro teórico e metodológico". Tradução de Luciana Salgado e Sírio Possenti. São Paulo: Parábola Editorial, 2010.

${ }^{7}$ Maingueneau remete ao texto Les énoncés détachés dans la presse écrite. De la surassertion à l'aphorisation (MAINGUENEAU, 2006, p. 107-120).

8 Alguns tradutores têm traduzido a forma francesa dé-textualisation como descontextualização. Optamos por destextualização, pois embora essa forma ainda não esteja dicionarizada em português, expressa de maneira mais fidedigna a categoria analítica proposta por Maingueneau.
}

BARONAS - Enunciados de curta extensão... 
é retirada do texto e, ao ser destextualizada ganha autonomia de sentido em relação ao contexto situacional em que foi primeiramente produzida e ao cotexto em que inicialmente estava inscrita.

Consideremos mais um fragmento, agora de autoria de Ana Flor, publicado no site do UOL em 31/05/2010 às 15h40:

\section{ii) Dilma sinaliza que, se eleita, poderá estender tempo de contribuição à Previdência}

A pré-candidata do PT à Presidência, Dilma Rousseff, sinalizou nesta segunda-feira que, se eleita, poderá propor mudanças na Previdência Social que incluam um prazo mais longo de contribuição. "O tal do bônus demográfico nada mais é do que isso: a sua população em idade de trabalho ativo é maior que sua população dependente, jovem, criança e velho. Mas a terceira idade, a terceira idade está ficando difícil... A gente vai ter que estender ela um pouco mais para lá", disse Dilma à imprensa na saída do fórum "Brasil - A construção da $5^{a}$ maior economia do mundo".

No fragmento anterior, põe-se em relevo um suposto excerto da fala da locutora Dilma Rousseff, colocando-o em forma de título do artigo: "Dilma sinaliza que, se eleita, poderá estender o tempo de contribuição à Previdência". Todavia, esse destaque é produzido pelo enunciador jornalista modulando enunciativamente a fala da locutora Dilma Rousseff: "O tal do bônus demográfico nada mais é do que isso: a sua população em idade de trabalho ativo é maior que sua população dependente, jovem, criança e velho. Mas a terceira idade, a terceira idade está ficando difícil... A gente vai ter que estender ela um pouco mais para lá". A locutora Dilma Rousseff efetivamente não textualizou que "se eleita, poderá estender o tempo de contribuição à Previdência". Entre a fala do enunciador jornalista e a fala da locutora não há fidelidade enunciativa. Ou seja, o enunciador não retomou textualmente as falas da locutora Dilma presentes no cotexto do artigo. Na verdade, embora tenha se utilizado de um verbo que não implica um total comprometimento do sujeito com o que enuncia, no caso o verbo 
"sinalizar", o jornalista realizou todo um trabalho de sobreasseveração da fala anterior, mudando sensivelmente o seu sentido. Nesta sobreasseveração temos um procedimento que não apenas põe em evidência um enunciado que foi dito por um locutor diferente do enunciador jornalista, mas um procedimento que se constitui numa tomada de posição no interior de um conflito de interpretações. Ou seja, o enunciador jornalista, ao recortar um fragmento da fala do outro, está interpretando a fala desse outro e no mesmo processo direcionando o público a aderir a essa interpretação.

Consideremos mais um fragmento publicado no site do UOL em 07/07/2010 - 14h58 de autoria de Maurício Simionato.

\section{iii) Serra chama de "incrível" Dilma assinar programa do PT sem ler}

O candidato à Presidência do PSDB, José Serra, disse hoje em Jundiaí (SP), ter achado "incrível" a versão de que sua adversária, a petista Dilma Rousseff, tenha assinado uma versão do programa de governo dela sem ter "dado uma olhada naquilo". A primeira versão do programa de governo petista foi entregue anteontem no TSE (Tribunal Superior Eleitoral). O documento previa, entre outros pontos, a tributação de grandes fortunas e redução de jornada de trabalho. Após repercussão na internet, o PT retirou sete horas depois de protocolado o documento e entregou outra versão. "Eu achei incrível realmente porque você não assina um programa assim, sem dar uma olhada naquilo que tem. $\mathrm{Na}$ verdade, eu acho que a proposta era entregar aquele mesmo. Não foi entregue outra versão. Demorou muito. Foi entregue uma versão trabalhada para tirar estas coisas um pouco mais polêmicas que são autenticamente ideias do PT, afinal de contas foram aprovadas em um "congresso do partido", disse Serra.

No excerto em análise, o locutor José Serra diz: "Eu achei incrível realmente porque você não assina um programa assim, sem dar uma olhada naquilo...", no entanto, o enunciador destaca somente o elemento 
linguístico "incrível": "Serra chama de "incrível” Dilma assinar programa do PT sem ler", colocando entre aspas no título da matéria. Além de o jornalista suprimir todo o restante do enunciado, ele constrói um enunciado que, embora seja atribuído ao candidato Serra, pelo cotexto original, é possível constatar que o locutor falou algo diferente do lhe foi atribuído. $\mathrm{O}$ enunciador jornalista se constitui num sobreasseverador que se sobrepõe tanto ao seu leitor quanto ao outro locutor cuja fala recorta, mostrando uma imagem de si, um ethos de um sujeito autorizado a realizar o trabalho de destaque da fala da outro. Trabalho esse que é realizado sob a validação da instituição midiática, no caso em análise, do UOL, que estabelece valores para além das interações e das argumentações. Trata-se de um trabalho de direcionamento de sentidos, de constituição de subjetividades em que, sem que se dê conta, o leitor é levado a aderir à interpretação do enunciador jornalista e, por extensão, ao posicionamento do veículo midiático no qual esse jornalista está inscrito.

\section{AFORIZAÇÃO E ENUNCIADOS DE PEQUENA EXTENSÃO}

No entendimento de Maingueneau (2010a), há enunciações que se inscrevem na ordem do texto e enunciações que se inscrevem na ordem da aforização. Estes dois tipos de enunciações se diferenciam pela maneira mesmo como lidam com a ordem do enunciável, do que pode e deve ser dito em uma determinada situação. Não se trata apenas de uma diferença de forma: por exemplo, marcas explícitas de citação do discurso do "outro" no fio do discurso do "eu", por exemplo: conjunção integrante, mais verbo dicendi, travessão e aspas para o texto; e marcas implícitas de citação para a aforização, como o discurso indireto livre. Para o pesquisador francês, entre texto e aforização é possível pensar nas seguintes oposições:

- Todo gênero de discurso define duas posições correlativas, de produção e de recepção, em interação e especificadas pelas restrições da cena genérica. O que faz com que possamos falar de "papéis". Poderíamos também dizer que na textualização não nos 
relacionamos com Sujeitos, mas com facetas, aquelas que são pertinentes para a cena verbal, onde a responsabilidade do dizer é partilhada e negociada. $\mathrm{Na}$ enunciação aforizante, em contrapartida, não há posições correlativas, mas uma instância que fala a uma espécie de "auditório universal" (Perelman), que não se reduz a um destinatário localmente especificado: a aforização institui uma cena de fala onde não há interação entre dois protagonistas colocados no mesmo plano. O locutor não é apreendido por tais ou tais facetas, mas em sua plenitude imaginária: não há ruptura entre uma instância fora da enunciação e uma instância que é um papel discursivo. É o próprio indivíduo que se exprime, além/aquém de qualquer papel, "ele mesmo", de alguma forma. Fundamentalmente monologal, a aforização tem como efeito centrar a enunciação no locutor;

- Um texto é uma rede de pensamentos articulados por meio das restrições de jogos de linguagem de diversas ordens: argumentar, narrar, responder a uma pergunta, maldizer... $\mathrm{Na}$ aforização, o enunciado pretende exprimir o pensamento de seu locutor, aquém de qualquer jogo de linguagem: nem resposta, nem argumentação, nem narração, mas pensamento, dito, tese, proposição, afirmação soberana...;

- Os textos tendem a estratificar planos enunciativos: diferentes figuras de enunciador (por exemplo, a autocorreção, a concessão...), diferentes status polifônicos (citações...), diferentes planos de texto (primeiro plano/plano de fundo...), enunciados embreados e desembreados... $\mathrm{Na}$ enunciação aforizante, ao contrário, o enunciado tende à homogeneidade, sem mudanças de planos enunciativos;

- Todo texto implica uma forma de subjetividade que varia segundo os suportes e os modos de circulação: será aquela que a escrita impõe. Mas a aforização passa ao largo de todas as oposições midiológicas. É uma forma de dizer puro, quase próxima de uma consciência;

- O texto excede a dimensão propriamente verbal: na forma escrita, ele é feito imagem (o que a tipografia manifesta), na forma oral, é um elemento num fluxo de comunicação (gestos, entoações, roupas...): a orquestra em que cada um toca sua parte. O enunciado aforizado, no entanto, não se desdobra para formar um quadro; ele contesta a inevitável espacialização da memória 
discursiva que cada texto constrói. Dessa forma, a aforização pretende escapar ao fluxo de comunicação, ser pura palavra;

- A enunciação textualizante resiste à apropriação por uma memória. É preciso ser ator ou bardo profissional para memorizar textos inteiros. A enunciação aforizante implica a utopia de uma palavra viva sempre disponível, que atualiza o "memorável": enunciando e mostrando que enuncia, ela se dá como parte de uma repetição constitutiva. (MAINGUENEAU, 2010a, p. 13-14).

Tomemos mais um excerto de texto publicado no site do UOL em 12/05 às $11 \mathrm{~h} 54$.

iv) Aborto é questão de política de saúde pública, diz Dilma

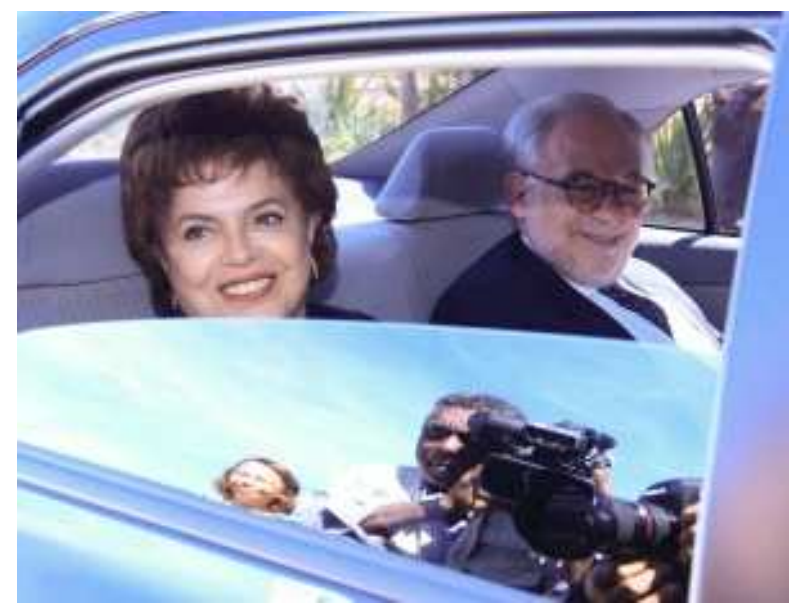

Dilma participou de programa de TV no Rio Grande do Sul nesta segunda-feira. Para a presidenciável Dilma Rousseff, o aborto é uma "violência contra a mulher" e não uma "questão de foro íntimo", mas sim uma de "política de saúde pública". A exministra da Casa Civil foi questionada sobre o tema na manhã desta quarta-feira (12), durante participação no programa Painel RBS, da emissora TVCOM, no Rio de Grande do Sul. "Nesses casos que incluem gravidez risco de vida ou violência não é 
possível que as mulheres das classes populares usem métodos medievais [para abortar]", disse a pré-candidata petista à Presidência da República. "Um governo não tem de ser contra ou a favor do aborto; ele tem de ser a favor de uma política pública".

Neste fragmento de texto é possível observar que o enunciado "aborto é questão de política de saúde pública" é destacado do contexto situacional e do cotexto original e colocado como título da matéria. A opção por esse destaque da fala da locutora em detrimento de outras possíveis tais como "violência contra a mulher" e "questão de foro íntimo" inicialmente parece estar relacionada ao fato de que essa pequena frase possui um caráter de fórmula. Todavia, um exame um pouco mais minucioso das outras falas evidencia que todas podem ser enquadradas na categoria de fórmula. Acreditamos que tal destaque se dê em razão de o jornalista se constituir num aforizador, pois como diz Maingueneau (2010a, p.14), o enunciador "assume o ethos do locutor que está no alto, do indivíduo autorizado, em contato com uma Fonte Transcendente. Ele é considerado como aquele que enuncia sua verdade, que prescinde da negociação”. O jornalista aforizador, ao realizar o destaque, não está dialogando nem com o locutor da fala destacada e nem com o destinatário (leitor). Sua fala monologalmente construída se inscreve como a fala autorizada de um Sujeito pleno de direito.

Se a aforização implica um locutor que se situa como Sujeito de pleno direito, reciprocamente um Sujeito se manifesta como tal por sua capacidade de aforizar. Trata-se fundamentalmente de fazer coincidir sujeito da enunciação e Sujeito no sentido jurídico e moral: alguém se coloca como responsável, afirma valores e os princípios perante o mundo, dirige-se a uma comunidade que está além dos alocutários empíricos que são seus destinatários. $\mathrm{Na}$ tradição filosófica, o Sujeito, o sub-jectum, é colocado abaixo, ele é o que não varia, o que escapa à relatividade dos contextos; Sujeito pleno, o aforizador pode responder por aquilo que diz através da pluralidade das situações de comunicação. Disso vem sua ligação estreita com a juridicidade: quando se quer condenar por suas afirmações, em geral o que se condena não é um texto - sempre relativo a um contexto -, mas uma aforização ou um conjunto de aforizações. (MAINGUENEAU, 2010a, p. 15). 
No momento em que o site do UOL insere monologalmente a aforização "aborto é questão de política de saúde pública", atribuída à candidata Dilma Rousseff, o leitor é interpelado a atribuir a esse enunciado formulaico um sentido que extrapola o seu sentido primeiro. A interpretação assume a equação: "Dizendo X, o locutor implica Y", onde $\mathrm{Y}$ se constitui num enunciado genérico de valor deôntico: " $\mathrm{O}$ Estado não deve deixar que o indivíduo decida sobre realizar um aborto ou não"; "O aborto deve ser tratado pelo Estado"; "O Estado deve planejar ações para resolver o problema do aborto"; "Não se deve apoiar o aborto", "O aborto não deve ser tratado como um problema religioso", etc. As possíveis interpretações produzidas pelos leitores não são da mesma ordem e profundidade das que acompanham os textos literários, filosóficos, ou religiosos, por exemplo. No entanto, trata-se de uma verdadeira "atitude hermenêutica" que faz com os leitores mobilizem um conjunto de estratégias interpretativas. Ou seja, os leitores são mobilizados a interpretar o destaque, procurando (re)construir o percurso interpretativo desenhado pelo aforizador. Desse modo, no entendimento de Maingueneau (2010a, p. 15),

[...] partindo do postulado de que a aforização resulta de uma operação de destacamento que é pertinente, o leitor deve construir interpretações que permitam justificar esta pertinência. Pouco importa qual seja a interpretação que ele construa, o essencial é que ele postule um além do sentido imediato e aja de acordo. Fazendo isso, o destinatário é chamado a justificar, pela busca hermenêutica, a própria operação de destacamento: o fato de esse enunciado ["aborto é questão de política de saúde pública"] ser apresentado em um regime aforizante leva o destinatário a legitimar a totalidade do quadro situacional.

No fragmento em análise, é possível observar ao lado da enunciação aforizante a presença de uma fotografia do rosto da locutora Dilma Rousseff. Sobre a relação entre fotografia e aforização, Maingueneau (2010a, p.16) nos diz o seguinte:

A presença muito frequente de fotos do rosto dos locutores ao lado das aforizações pessoais aparece como a manifestação de algo constitutivo. O rosto tem duas propriedades notáveis: 1) é a única parte do corpo considerada capaz de identificar o indivíduo 
como distinto de qualquer outro; 2) é, no imaginário profundo, a sede do pensamento e dos valores transcendentes. A foto autentica a aforização do locutor como sendo sua fala, aquela que faz dele um Sujeito plenamente responsável. Ela acompanha

No caso em análise, a fotografia mostra que a locutora Dilma Rousseff está dentro de um carro acompanhada por Marco Aurélio Garcia, assessor especial da Presidência da República para assuntos internacionais. A matéria do jornalista faz, contudo, alusão ao fato de que a candidata deu entrevista a uma TV do Rio Grande do Sul, "Dilma participou de programa de TV no Rio Grande do Sul nesta segundafeira"; era de se esperar, portanto, que a fotografia retratasse a entrevista. No entanto, como afirma Maingueneau (2010a, p. 16) "A foto do rosto também é, além disso, o produto de um destacamento, que elimina a exigência de todo contexto situacional (roupa, lugar, momento...)". A fotografia do rosto da locutora Dilma Rousseff apaga a necessidade de uma referencialidade, corporal, temporal e espacial. Não é preciso mostrar a locutora em um estúdio de televisão para evidenciar que efetivamente ela tenha dito o que está no destaque e no cotexto original. Tanto a aforização quanto o destacamento do rosto, ao se apoiarem mutuamente, identificam o locutor com a pessoa do rosto, dando corpo à enunciação e produzindo um efeito de veracidade do que é dito.

Tomemos mais um excerto de matéria publicada no site do UOL em 13 de setembro de 2010 às 14h57, de autoria de Camila Campanerut.

v) Serra satiriza argumento de Dilma "de que não era candidata em 2009"

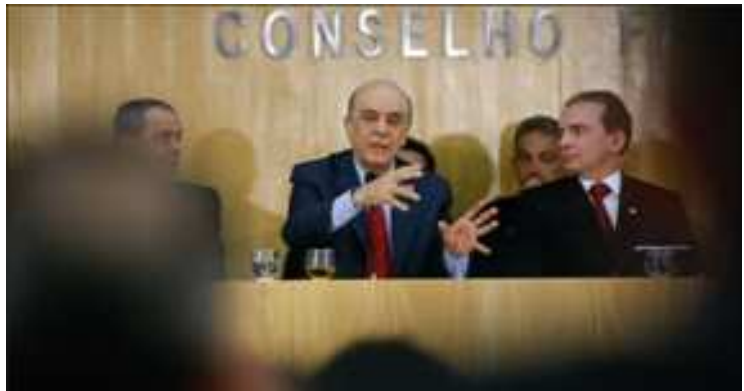

BARONAS - Enunciados de curta extensão... 
O candidato à Presidência da República, José Serra (PSDB), disse segunda-feira (13) que o argumento de sua principal concorrente na disputa eleitoral, a ex-ministra-chefe da Casa Civil, Dilma Rousseff (PT) de que o vazamento de dados sigilosos da Receita Federal de aliados dele não tem ligação com as eleições é "hilariante". "É muito importante saber que está ligado a uma questão político-eleitoral. A idéia de que ela não era candidata é hilariante. A Dilma já, desde meados de 2008 começou a campanha ao lado do presidente da República, inclusive quem tocava a Casa Civil na prática era a atual ministra da Casa Civil. Isso até as paredes, o gramado da Esplanada, as lâmpadas da OAB, todo mundo sabe disso", afirmou após participação de debate na sede do Conselho Federal da Ordem dos Advogados do Brasil (OAB). Logo após receber a notícia do vazamento de dados da filha de Serra, a empresária Verônica Serra e de seu genro Alexandre Bourgeois, Dilma alegou que não era candidata e, que por isso os vazamentos de dados fiscais de pessoas ligadas a Serra não tinham viés eleitoral.

"Em abril de 2009 não existia eleição, nem para mim, nem para o meu adversário, nem para a outra concorrente, a Marina. Nenhum de nós era candidato, era algo bastante longe. Então tem de apurar direitinho o que está acontecendo dentro da Receita. Em setembro, eu não era candidata, não era précandidata, não tinha pré-candidatura nem candidatura", afirmou a petista, no último dia 5 em entrevista coletiva.

No fragmento em análise o locutor José Serra diz: “É muito importante saber que está ligado a uma questão político-eleitoral. A ideia de que ela não era candidata é hilariante. A Dilma já, desde meados de 2008 começou a campanha ao lado do presidente da República, inclusive quem tocava a Casa Civil na prática era a atual ministra da Casa Civil. Isso até as paredes, o gramado da Esplanada, as lâmpadas da $\mathrm{OAB}$, todo mundo sabe disso". Todavia, o jornalista constrói o título da matéria introduzindo o enunciado "Serra satiriza o argumento de Dilma" e destacando do cotexto original a pequena frase "de que não era candidata", todo o restante da fala do locutor é totalmente opacificada. Além disso, no cotexto original, embora tenha qualificado de hilariante "a idéia de que não era candidata", não fica tão evidente que o locutor 
José Serra tenha satirizado o argumento de Dilma Rousseff. Com efeito, quando o site do UOL reconstrói a fala atribuída ao candidato José Serra, o leitor é interpelado a atribuir a esse enunciado um sentido que extrapola o seu sentido primeiro. A interpretação assume a equação: "Dizendo X, o locutor implica Y", onde Y se constitui num enunciado genérico de valor deôntico: "O argumento de Dilma não deve ser entendido como verdadeiro"; "Dilma deve falar a verdade sobre a quebra de sigilo na Receita Federal"; "Não se deve apoiar quem falta com verdade", etc. Trata-se, tal qual no exemplo anterior, de uma verdadeira "atitude hermenêutica" que faz com que os leitores mobilizem um conjunto de estratégias interpretativas. Ou seja, os leitores são mobilizados a interpretar o destaque, procurando (re)construir o percurso interpretativo desenhado pelo aforizador, independentemente das falas dos locutores.

Ao lado do fragmento em análise é possível constatar uma fotografia do locutor José Serra, evidenciando a sua participação em debate na sede do Conselho Federal da OAB em Brasília. Esta fotografia, além de dar credibilidade ao que foi enunciado pelo jornalista, ou seja, que a fala do locutor Serra é efetivamente dele, dando corpo à enunciação, sustenta o caminho interpretativo dado por este jornalista ao leitor.

Consideremos mais um fragmento publicado no site do UOL em $12 / 09 / 2010$ às $22 \mathrm{~h} 06$.

\section{vi) Dilma evita dizer se colocaria a mão no fogo por Erenice Guerra}

A candidata do PT à Presidência, Dilma Rousseff, evitou dizer se colocaria a mão no fogo pela ministra da Casa Civil e seu braço direito, Erenice Guerra. Ela também afirmou que não pode ser responsabilizada pelo filho de uma ex-assessora. "Não concordo, não vou aceitar que se julgue a minha pessoa baseado no que aconteceu com o filho de uma ex-assessora minha", disse Dilma, ao ser questionada pela jornalista Renata Lo Prete no debate Folha/RedeTV!. Para ela, o governo deve apurar de forma rigorosa a denúncia da revista "Veja" de que o filho da ministra Israel Guerra fez lobby para ajudar a MTA Linhas Aéreas a renovar concessão da Anac, o que permitiu um contrato com os 
Correios. Dilma disse que o caso é mais uma manobra eleitoreira sistematicamente feita contra ela. Os escândalos do governo Lula dominaram o debate nos três primeiros blocos. Na sua primeira fala, por exemplo, José Serra (PSDB) citou esses escândalos. "O maior fracasso foi o mensalão, o dossiê dos aloprados, e agora essas violações da Receita." José Serra também fez um duro ataque ao governo Lula e à petista. "É assunto do governo, que acoberta os companheiros e persegue a oposição. A democracia do PT, da Dilma, a democracia deles, é usar o aparato legal para proteger os companheiros", afirmou o tucano. Questionado por que não falou antes da suspeita de que o sigilo fiscal tinha sido violado, Serra respondeu que suspeitava, mas não tinha prova. "Não cabe a mim colocar rumores. Se eles fazem isso hoje na campanha imagine amanhã." No terceiro bloco, Dilma pediu um direito de resposta e foi atendida. Pela sua resposta, Serra também quis o direito e também foi atendido.

O título da matéria em análise, "Dilma evita dizer se colocaria a mão no fogo por Erenice Guerra", mobiliza um provérbio corrente na nossa sociedade: "pôr a mão no fogo por alguém". Todavia, no cotexto original não é possível recuperar que a locutora Dilma Rousseff tenha dito esse provérbio, ou mesmo evitado dizer que colocaria a mão no fogo pela sua ex-assessora. O que está textualizado de fato no cotexto é a fala do enunciador jornalista: "A candidata do PT à Presidência, Dilma Rousseff, evitou dizer se colocaria a mão no fogo pela ministra da Casa Civil e seu braço direito, Erenice Guerra". Na sequência o enunciador diz: "Ela também afirmou que não pode ser responsabilizada pelo filho de uma ex-assessora". O enunciado "Ela também afirmou...", se por um lado apresenta uma informação nova, por outro, mediante a utilização do advérbio também, dialoga com a construção anterior inscrevendo os dois enunciados como sendo de responsabilidade de um único enunciador. Dessa forma, apesar de essa afirmação não ter sido proferida pela candidata, da maneira mesmo como o enunciador organizou a sua fala, tais enunciados passam a se constituir como se fossem afirmações da locutora Dilma. No cotexto o que Dilma diz efetivamente é: "Não concordo, não vou aceitar que se julgue a minha pessoa baseado no que aconteceu com o filho de uma ex-assessora minha". 
O exemplo arrolado apresenta um tipo de aforização bastante diferente, pois foi o locutor José Serra, em entrevista em Brasília ${ }^{9}$, que disse "Ela não pôs a mão no fogo [por Erenice], mas ao mesmo tempo botou tudo dizendo que era um jogo eleitoral. Ela disse xis e menos um sobre xis na mesma fala. Ela não botou a mão no fogo, por um lado, e por outro disse que era uma jogada eleitoral. Ou seja, atacou aqueles que denunciaram. Quem denunciou, passa a ser culpado". O título da matéria em questão é um enunciado do locutor Serra em um contexto situacional totalmente diferente do apresentado pelo enunciador jornalista. Trata-se de uma aforização bastante peculiar, visto que o enunciador jornalista enxerta uma fala que é do locutor Serra e que foi produzida em outro contexto situacional numa espécie de projeção enunciativa irrealizada da locutora Dilma. Em outros termos, o jornalista transfere uma fala do locutor Serra produzida em outro contexto e a atribui à locutora Dilma, responsabilizando-a por algo que ela não disse. Todavia, esse trabalho de destaque da fala de Serra e inserção na fala de Dilma é totalmente opacificado. Com efeito, quando o site do UOL diz que "Dilma evita dizer se colocaria a mão no fogo por Erenice Guerra", o leitor é interpelado a atribuir a esse enunciado um sentido que extrapola o seu sentido primeiro. A interpretação assume, tal qual nos excertos anteriores, a equação: "Dizendo X, o locutor implica Y", onde Y se constitui num enunciado genérico de valor deôntico: "Uma candidata a presidente deve se comprometer com as ações dos seus subordinados"; "As ações da ex-assessora e da própria Dilma na Casa Civil não devem ser consideradas como dignas de confiança", "Dilma e a ex-assessora devem ser responsabilizadas pelo que aconteceu", etc. Trata-se, tal qual nos exemplos anteriores, de uma verdadeira "atitude hermenêutica", que faz com que os leitores ou os ouvintes mobilizem um conjunto de estratégias interpretativas. Ou seja, os leitores são mobilizados a interpretar o destaque, procurando (re)construir o percurso interpretativo desenhado pelo aforizador, independentemente das falas dos locutores.

\footnotetext{
${ }^{9}$ Em matéria de Robson Bonin Do G1, em Brasília: "O candidato do PSDB à Presidência da República, José Serra, afirmou que a candidata petista Dilma Rousseff "não colocou a mão no fogo" pela ministra-chefe da Casa Civil, Erenice Guerra, "mas ao mesmo tempo botou tudo" ao dizer que as denúncias contra a integrante do governo tinham motivação eleitoral".
} 


\section{APONTAMENTOS EM FORMA DE CONCLUSÃO...}

Do mirante da análise discursiva dos pequenos enunciados atribuídos aos candidatos Dilma Rousseff e José Serra à luz, sobretudo, das categorias de sobreasseveração e de aforização, propostas por Dominique Maingueneau, foi possível constatar que os destaques efetuados pelo jornalista aforizador, colocando-se como um sujeito autorizado, pleno de direito, cuja "verdade" veiculada prescinde de diálogo (quer seja com o locutor do texto destacado, quer seja com o próprio destinatário do texto), não apenas insta o leitor a realizar uma interpretação, mas propõe para este leitor um percurso interpretativo. $\mathrm{O}$ que implica uma espécie de "cumplicidade"10 interpretativa entre aforizador e destinatário. Cumplicidade que possibilita a construção de determinadas subjetivações nos sujeitos: por exemplo, votar ou não em determinado candidato; culpar ou não determinado sujeito por um crime, etc.

Embora em alguns dos fragmentos analisados não se possa recuperar quais foram os sujeitos jornalistas que produziram as matérias, é possível encontrar uma espécie de regularidade autoral em todos os fragmentos analisados. Retomemos os títulos dos seis fragmentos:

a) Em entrevista no Ceará, Serra diz que "pesquisa vai e vem";

b) Dilma sinaliza que, se eleita, poderá estender tempo de contribuição à Previdência;

c) Serra chama de "incrível” Dilma assinar programa do PT sem ler;

d) Aborto é questão de política de saúde pública, diz Dilma;

e) Serra satiriza argumento de Dilma "de que não era candidata em 2009";

f) Dilma evita dizer se colocaria a mão no fogo por Erenice Guerra.

${ }^{10}$ Cumplicidade que é "extremamente perversa, pois isenta o enunciador jornalista de qualquer responsabilidade pelo destacamento que realizou da fala do locutor". (Dominique Maingueneau, intervenção no II Fórum Internacional de Análise do Discurso, realizado no período de 08 a 10 de setembro de 2010 na UFRJ no Rio de Janeiro). 
É possível constatar que os destaques realizados seguem uma mesma regularidade discursiva: colocam a locutora Dilma tendo que dar explicações sobre algum fato político ou proposta de governo e, no mesmo processo, o locutor Serra ora como o inquiridor desses fatos e ora como alguém que não está preocupado com as pesquisas de intenção de votos. A locutora Dilma é sempre apresentada como alguém que está sendo interpelada a dar explicações em determinado processo e o locutor Serra como um representante autorizado pela sociedade, uma espécie de representante do Ministério Público com o direito de inquiri-la. Essa forma de organizar as diferentes vozes dos locutores Dilma e Serra, isto é, essa marca de autoria institucional, deixa menos opaco o lugar ideológico ocupado pelo site do UOL na fabricação do fazer jornalístico das eleições presidenciais 2010 .

Do ponto de vista teórico da Análise de Discurso, a aforização evidencia, por um lado, que se deve levar em consideração, numa análise discursiva da citação, não só o uso de aspas, a escolha de verbos dicendi para a demarcação dos contornos dos textos e para a atribuição das responsabilidades enunciativas, mas, também, todo o trabalho de destaque de um determinado fragmento textual e, por outro, que essa destextualização de pequenos enunciados implica outra ordem do enunciável, na qual dialogam tensivamente não somente locutores e enunciadores, mas também Sujeitos plenos de direito, e que estes últimos se sobrepõem enunciativamente aos outros dois.

\section{REFERÊNCIAS}

BAKHTIN, M. Esthétique de la création verbale. Paris: Gallimard, 1984. KRIEG-PLANQUE, A. «Purification ethnique ». Une formule et son histoire. Paris: CNRS Éditions, 2003. Collection Communication, 2003.

. A noção de "fórmula" em análise do discurso - quadro teórico e metodológico. Tradução de Luciana Salgado e Sírio Possenti. São Paulo: Parábola, 2010.

MAINGUENEAU, D. Les énoncés détachés dans la presse écrite. De la surassertion à l'aphorisation. In: BONHOMME, M. ; LUGRIN, G. (Éds.). Interdiscours et intertextualité dans les médias. Travaux Neuchâtelois de Linguistique, n. 44, p.107-120, septembre 2006. 
Citação e destacabilidade. In: Cenas da enunciação. Org. Sírio Possenti e Maria Cecília Perez de Souza-e-Silva. Curitiba, PR: Criar Edições, 2007.

- Aforização: enunciados sem texto? In: Doze conceitos em análise do discurso. Org. Sírio Possenti e Maria Cecília Perez de Souza-e-Silva. São Paulo, SP: Parábola Editorial, 2010a.

. Aphorisations politiques, médias et circulation des énoncés. 2010b. (no prelo para publicação).

Recebido em 28/09/10. Aprovado em 05/04/11.

Title: Short enunciations: Discourse genres, aphorization, media and politics Author: Roberto Leiser Baronas

Abstract: The main goal in this study is to try and understand the role of the mediatic machine in the process of production, distribution and making of the political information in the 2010 Brazilian presidential elections. For such, an analysis was made based on Discourse Analysis, more specifically the works by Dominique Maingueneau (2007, 2010a e 2010b), of a corpus constituted by short enunciations attributed to the then candidates Dilma Roussef and José Serra as presented by the Brazilian electronic media in 2010. Initially a definition was presented of the characteristics of the "short enunciation", in order to make a distinction between it and other enunciations like slogans and proverbs. In a second, move the enunciative characteristics of such short sentences that intend to call attention were evinced, as well as the genre, linguistic and semiotic determinants employed by the mediatic actors as they stressed these short enunciations. Finally, a description is made of how such enunciations are put out of the original context, in a move to understand how they are subjected to the discursive regime of aphorization.

Keywords: Political discourse. Short enunciation. Aphorization and media.

Título: Enunciados de corta extensión: género de discurso, apotegma, medios y política Autor: Roberto Leiser Baronas

Resumen: Resumen: Nuestro primero interés en este trabajo es intentar comprender el papel de la máquina mediática en los procesos de producción, circulación y de fabricación de las informaciones politicas sobre las elecciones presidenciales brasileñas de 2010. Para tanto, anclados en el Análisis del Discurso, más especificamente en los trabajos de Dominique Maingueneau (2007, 2010a y 2010b), frecuentamos un corpus constituido por pequeños enunciados atribuidos a los candidatos Dilma Rousseffy José Serra y vehiculados por los medios electrónicos brasileños en 2010. Inicialmente, buscamos definir las características del "enunciado de corta extensión", diferenciándolo de otros como slogans y proverbios; en un segundo momento, evidenciamos, por un lado, las características enunciativas de esas pequeñas frases que visan favorecer su destaque y, por otro, los determinantes genéricos, linguísticos y semióticos utilizados por los locutores mediáticos en el destaque de esos enunciados y, por último, describimos como esos enunciados son destextualizados de sus cotextos originales, procurando comprender como son sometidos al régimen discursivo del apotegma.

Palabras-clave: Discurso político. Enunciado de corta extensión. Apotegma y medios. 